\title{
Opinião
}

\section{PERFIL DO PROFISSIONAL DE SAÚDE PARA ATUAR NAS POLÍTICAS SOBRE DROGAS: REABILITAR OU REDUZIR OS DANOS?}

\author{
Francisca Ergovânia Batista de Brito (1)
}

\begin{abstract}
Que perfil de profissionais de saúde deve atuar na atenção aos usuários de álcool e drogas? Estes profissionais se encontram habilitados e capacitados mentalmente para a prestação de cuidados específicos com estes pacientes? A reabilitação está sendo atuada corretamente e específica para cada usuário de drogas que busca os serviços de saúde? Quais os conhecimentos em políticas sobre drogas vigentes no Brasil pelos profissionais? É quase impossível separar o particular do profissional, com isso percebem-se falhas na seleção desses profissionais em prestação de cuidados dos usuários de drogas ilícitas. Essas perguntas são norteadoras, mais do que meros elementos práticos sobre a problemática em questão é a sua inserção em uma sociedade que se sente quase impotente diante da proporção que cresce em números de consumidores e traficantes de substâncias ilícitas nas ruas. A nova Política Nacional Sobre Drogas abrange uma contextualização no ponto de vista clínico e menos repressivo na abstenção do uso de drogas. O objetivo proposto é ressaltar a relevância da formação técnica do redutor de danos a uma necessidade e por isso o redutor precisa ter uma qualificação articulada à atenção básica.
\end{abstract}

\section{Políticas públicas sobre drogas no Brasil}

A dependência das drogas é transtorno onde predomina a heterogeneidade, já que afeta as pessoas de diferentes maneiras, por diferentes razões, em diferentes contextos e circunstâncias. Muitos consumidores de drogas não compartilham da expectativa e desejo de abstinência dos profissionais de saúde, e abandonam os serviços (MINISTÉRIO DA SAÚDE, 2001).

A droga é "o inimigo público número um do século XXI". Esta foi a frase publicada nos jornais, em 1997/98, durante a visita de Bill Clinton ao Brasil, reafirmada pela direção da Secretaria Nacional Antidrogas (SENAD). A política sobre drogas no Brasil é confundida com a Lei. 368/76 durante a ditadura militar em nosso país, 1964. Esta lei, até hoje, regulamenta o uso, a produção e a venda de drogas definidas como ilícitas. Sendo assim, há tempos percebe-se a influência desta política exposta em uma contextualização individualizada do tema prejudicando a sociedade no modelo econômico e social. 
Alguns artigos desta Lei são bastante expressivos dessa cultura: relata sobre a participação efetiva do cidadão no combate ao tráfico de drogas ilícitas e que o uso destas substâncias é considerado uma doença para quem consome e um crime hediondo para quem comercializa, sendo assim, não importa a quantidade consumida ou traficada, pois ambos modos de vida causa danos, muitas vezes, irreversíveis a sociedade em termos econômicos e sociais.

Segundo a autora Paulina Duarte:

A política sobre drogas no Brasil começou a ser pensada em 1988. Foi criada a Secretária Nacional Antidrogas (SENAD), e a política ainda buscava a perspectiva de um mundo sem drogas. $O$ que devemos buscar são as melhores formas de prevenção, controle, tratamento às pessoas que precisam e repressão ao tráfico. (DUARTE, P. 2011- p. 20)

Quando falamos em combate às drogas, imaginamos erradicar o tratamento com abstinência e quase sempre esse tratamento é falido, pois os profissionais estão fadados a ignorar o modo de vida do usuário de drogas ilícitas. A questão das drogas na sociedade é muito mais complexo do que simplesmente fazer com que cesse o uso delas. Por isso, é necessário a diversificação de uma política pública precisa e eficaz, precisamos criar alternativas para os que não conseguem abstinência, entretanto o tratamento visando a abstinência é relevante.

Reafirma-se no programa da SENAD, o combate ao tráfico de drogas e comercialização de substâncias entorpecentes e drogas que causem dependência psico-física - abrangendo a Lei 6.368/76. A dependência das drogas ilícitas são expostas como um prejuízo à segurança pública, à soberania dos Estados, uma ameaça a humanidade, identificadas como um mal em si (LEAL, L 2011).

Segundo o Ministério da Saúde, (2001), os Centros de Atenção Psicossociais de álcool e drogados (CAPSad) também podem ter a responsabilidade de organizar a rede local de serviços de atenção a usuários de álcool e drogas de seu território de atuação, a saber:1) Quando são a porta de entrada da rede de atenção a usuários de álcool e drogas, em sua área de atuação; 2) Quando o gestor local indica a unidade para coordenar as atividades de supervisão de serviços de atenção a usuários de drogas; 3) Devem ainda supervisionar e capacitar as equipes de atenção básica, serviços e programas de saúde mental, no âmbito de seu território; 4) Devem também manter listagem atualizada dos pacientes que, em sua região de abrangência, utilizem medicamentos para a saúde mental.

O CAPSad tem uma área de abrangência limitada, com a finalidade de ofertar atendimento à comunidade, oferecendo atividades preventivas, terapêuticas e inserção social. Os usuários de drogas que se utiliza destes serviços podem não chegar à abstinência, mas amenizar os danos causados pelas substâncias e ter uma qualidade de vida com atividades físicas, se alimentar, trabalhar e até mesmo estudar amenizando os efeitos maléficos.

\section{Profissionais de Saúde em reabilitação de dependentes químicos}

Toda essa explanação sobre políticas públicas nos vem o debate sobre o profissional apto a desenvolver um trabalho enriquecedor e específico para cada usuários de drogas. Para isso, faz necessário a qualificação do 
profissional de saúde em uma segunda formação em Técnico em Reabilitação de Dependentes Químicos. Essa formação, segundo o catálogo que segue, aborda elementos como: direitos humanos e legislação, bases bioquímicas, psicopatologias, redução de danos e inserção social, assim, com aptidão a atuar em situações emergenciais de intoxicações e abstinências.

Entretanto, este curso não está sendo ofertado em nenhuma instituição no Brasil, pois alegam ser um curso de custos altos e não possuírem recursos financeiros e não há uma procura continua da qualificação em Técnicos em Reabilitação de Dependentes Químicos.

Defendemos a atuação de um profissional que esteja mais atentos às novas políticas sobre drogas, reduzindo os danos a sociedade, com uma prática semelhante ao Agente Comunitário de Saúde (ACS). Portanto, com uma disposição de um acompanhamento domiciliar, já que não há, no momento, uma formação regulamentada e específica de redução dos danos econômico e social causados pelas drogas ilícitas. Abaixo o catálogo Nacional de Cursos Técnicos: ambiente, saúde e segurança:

\begin{tabular}{|c|c|c|}
\hline $\begin{array}{c}\text { POSSIBILIDADES DE TEMAS } \\
\text { A SEREM ABORDADOS NA } \\
\text { FORMAÇÃO }\end{array}$ & $\begin{array}{l}\text { POSSIBILIDADES DE } \\
\text { ATUAÇÃO }\end{array}$ & $\begin{array}{l}\text { INFRAESTRUTURA } \\
\text { RECOMENDADA }\end{array}$ \\
\hline $\begin{array}{l}\text { * Direitos humanos e legisla-ção } \\
\qquad \text { Bases bioquímicas e } \\
\text { neuroquímicas da dependên-cia } \\
\text { química } \\
\qquad \text { Psicopatologias } \\
\text { * Redução de danos e } \\
\text { reinserção social }\end{array}$ & $\begin{array}{l}\text { * Centros de atenção psicos-social } \\
\quad * \text { Serviços de referên-cia } \\
\text { em saúde mental } \\
\text { * Unidades básicas de } \\
\text { saúde } \\
\text { * Comunidades tera- } \\
\text { pêuticas }\end{array}$ & $\begin{array}{l}\text { * Biblioteca com acervo espe-cífico } \\
\text { e atualizado } \\
\qquad \text { Laboratório de pri- } \\
\text { meiros socorros } \\
\text { * Laboratório de infor- } \\
\text { mática com programas espe-cíficos } \\
\text { * Laboratório didáti-co: } \\
\text { unidades de saúde mental }\end{array}$ \\
\hline
\end{tabular}

Fonte: http://catalogonct.mec.gov.br/index.php: acessado: 21/04/2011 ás 15h57min PM.

Este catálogo aborda vários temas e possibilidades de atuação, participando no desenvolvimento e monitoramento de programas assistenciais na redução de danos causados por estas substâncias entorpecentes. A deficiência de técnicos qualificados se inicia na própria formação acadêmica, ou mesmo afirmar, ausência de formação.

Enfermeiros, psicólogos, médicos, assistentes sociais e pessoal de apoio na área de saúde, tendem em algum momento a trabalhar com usuários de substâncias entorpecentes. É nessa hora que percebemos a falta de qualificação técnica a desempenhar em profissionais que saem das universidades sem uma preparação específica nesta área de saúde mental, visto que o tema proposto é comum, freqüente e de um teor relevante na sociedade.

Os médicos são formados para tratar as consequiências fisiológicas das dependências, sem uma visão holística da doença. A visão holística das situações são mais vivenciadas pelos enfermeiros, mas com a mesma deficiência das demais categorias profissionais. Em psicólogos ou assistentes sociais existe uma grade curricular quase sem opções em saúde mental e que trata uma disciplina em todo o curso, caso exista, é com mínima carga 
horária que não despertam o interesse dos acadêmicos, visto que estão em um período frenético para acúmulos de créditos no final da graduação.

O que contribui para a ausência ou deficiência de formação de profissionais para lidar com usuários de álcool e outras drogas é a falta da obrigatoriedade no ensino superior dos profissionais de saúde. Se o graduando se interessar pelo tema terá que buscar cursos extracurriculares ofertados por instituições especializadas no tratamento de substâncias entorpecentes e com isso contribuir para a saúde econômica e social da sociedade.

\section{Considerações finais}

A resposta repressiva ainda faz parte da Política de drogas no Brasil. Essa resposta amplificada é pragmática na proposta de redução de danos e talvez encontre explicação na urgência de prevenção do HIV/AIDS dentre outras doenças, pois essas políticas requer revisão prioritária e eficazes. Não é só a questão do uso de drogas, mas o que o usuário pode adquirir e consequentemente transmitir outras enfermidades por estar vulneráveis a novos danos.

Medidas sociais preventivas dos "ganhos fáceis" não está abrangido pelo programa Antidrogas da política do governo. Portanto, o combate ao tráfico de varejo é o alvo pretendido com uma redução favorável a minimizar a circulação de entorpecentes.

A dependência como um processo complexo, que envolve alterações neurofisiológicas, componentes psicológicos e também sociais (VOMERO, 2001). Desta forma, dificultando mas não impossibilitando a reabilitação e inserção na sociedade do usuário de drogas.

Quanto ao perfil do profissional qualificado em lhe dar com esses cuidados: deveriam passar por uma política mais rígida em saúde mental. Que esses profissionais (médicos, psicólogos, enfermeiros, assistente social) fossem avaliados o seu psicossocial antes de lhe dar com esta problemática das drogas em serviços de saúde.

A opinião pública deve ser despertada para as mudanças ocorridas na sociedade pelo tráfico de drogas e usuários, assim, há uma necessidade de uma revisão imediata dos currículos de graduação em saúde, portanto, a política vigente possa formular uma grade curricular mais abrangente na área da saúde mental e de tratamentos com dependentes químicos.

Defendemos uma política que articule uma proposta de prevenção abrangente, preservadora dos direitos humanos e dentro da realidade, proporcionando cuidados aos usuários de drogas e minimizando os prejuízos a saúde, promovendo a inserção dos dependentes na sociedade e que motive empresários da comunidade de forma a proporcionar alternativas de vida e a evitar deixá-los entregues ao tráfico como forma de subsistência em uma vida desumana e a mercê da própria sorte.

\section{Referências}

ALMEIDA DE FIGUEIREDO, N. M. - Método e metodologia na Pesquisa científica. 3. Ed. Cap.5, p73-117, agosto 2009. 
BRASIL, MINISTÉRIO DA SAÚDE. Relatório do seminário sobre o atendimento aos usuários de álcool e outras drogas na rede do SUS. Caderno de Textos de Apoio da III Conferência Nacional de Saúde Mental. MS, Brasília, 2001

DUARTE, P. Reabilitar ou reduzir danos? Revista Poli saúde, educação, trabalho. Ano III, no. 16mar/abr.2011, p.20.

LEAL, L. Reabilitar ou reduzir danos? Revista Poli saúde, educação, trabalho. Ano III, no. 16- mar/abr.2011, p. $20-21$

VOMERO, M. F. Independência ou morte. Superinteressante, São Paulo, ano 15, n. 3, p. 51-55, mar. 2001

\section{Sobre a autora:}

(1) Francisca Ergovânia Batista de Brito é Bacharel em Administração de Empresa pela Faculdade Dr. Leão Sampaio em Juazeiro do Norte - CE. Enfermeira pela mesma instituição. Especialista em Adm. Hospitalar pela (URCA). Especializanda em Políticas Públicas em Saúde Coletiva (URCA). Técnica em Segurança e Saúde no Trabalho-SST (IBTF-Instituto Brasileiro de Educação e Tecnologia de Formação). Especializanda em Enfermagem do Trabalho (UVA).

E-mail: ergovaniabrito@hotmail.com

\section{Como citar este artigo (Formato ISO):}

BRITO, F.E.B. Perfil do profissional de saúde para atuar nas políticas sobre drogas: reabilitar ou reduzir os danos?. Id on Line Revista de Psicologia, Julho de 2011, vol.1, n.14, p.09-13. ISSN 1981-1189. 